\title{
The Complex Network Theory-Based Urban Land-Use and Transport Interaction Studies
}

\author{
Rui Ding (ii) \\ College of Big Data Application and Economics, Guizhou University of Finance and Economics, Guiyang, Guizhou, China \\ Correspondence should be addressed to Rui Ding; 396124877@qq.com
}

Received 29 January 2019; Revised 18 May 2019; Accepted 30 May 2019; Published 17 June 2019

Academic Editor: Émile J. L. Chappin

Copyright (C) 2019 Rui Ding. This is an open access article distributed under the Creative Commons Attribution License, which permits unrestricted use, distribution, and reproduction in any medium, provided the original work is properly cited.

\begin{abstract}
The research on complex networks offers novel insight into the analysis of complex urban systems. The objective of this article is to provide a review of complex network theory in urban land-use and transport studies to date. Some traditional integrated studies of urban land-use and traffic networks are summarized and analysed; related research gaps were proposed. Then, this paper reviewed the application of complex network theory in urban land-use and transport research and practice. It shows that the node importance identification method is critical for network protection or attack studies; the multiple centrality assessment and kernel density estimation approaches can be used to represent the intuitionistic connections of urban traffic networks and surrounding land-uses; it can be used to verify the changing trend and variation of landscape connectivity; also it can be applied to the identification of key changed land-use types in land-use cover change; the coevolution process can be treated as an integrated way to discuss the relationships between urban traffic network growth and land-use change, and the multilayer networks based analysis is a novel method to measure their interactions. This paper is essential in establishing apparent research interests and points out the further potential application of complex network theory in urban traffic network and land-use related studies.
\end{abstract}

\section{Introduction}

Many investigations have shown that, in the complex urban system, traffic networks, city-size distributions, distribution of urban traffic flows, and human mobility follow scaling properties [1-5]. Due to a rapid surge of interest since Watts and Strogatz [6], and Barabasi and Albert [7] pointed out the collective dynamics of small-world networks and scalefree networks; complex network theory has become a novel multidisciplinary research direction of complexity science. A small-world network is a type of network in which the network structure has a high clustering coefficient and a small average shortest distance. A scale-free network is a type of network in which the degree distribution of nodes obeys the power-law distribution. Considerable cross-disciplinary research and professional collaborations have focused on understanding, integrating, and applying complex network theory in terms of both empirical science and basic science. For now, complex network theory concentrates on the following aspects: the empirical research of network characteristics
[8]; network hub node detection [9]; network dynamics and spreading processes [10]; detection of communities and groups [11]; robustness and vulnerability [10, 12]; and multiplex network theory and applications [13]. Research into complex networks provides us with a novel way to analyse complex urban systems $[14,15]$. The viewpoints of the small-world network and scale-free network changed the thinking of urban traffic networks: before these two models were proposed, traffic networks were normally approached as regular networks and ER random networks [16], as inherited from the definitions of graph theory. Based on these recent studies, it has been observed that many urban traffic networks exhibit and obey small-world network properties [17-20] and scale-free network properties [21-23].

The purpose of this article is to provide a comprehensive review of the progress made in complex network theorybased urban land-use and transport studies to date. It is also worth mentioning that the history and some basic indicators and functions or models of these subjects (land-use, transportation, and networks) have been reviewed by numerous 
authors [17, 24-32]. In these reviews, the theoretical contexts for conceptual and existing empirical research of land-use and transportation have been discussed thoroughly, and most of the land-use and transport interaction (LUTI) models have been addressed. The complex network development processes, related theory, and research on urban traffic networks have been summarized by Ding, Ujang et al. [15]. Hence, this article will emphasize and further discuss complex network theory in the context of land-use and transport interaction studies and applications. Furthermore, I focus only on landuse models combined with traffic network structures. Other city problems and models such as pollution and social issues are not within the scope of the discussion, although some of these issues have direct connections to urban land-use planning.

The structure of the paper is as follows. First, I will review these traditional studies that integrate the urban land-use and traffic network. These studies grasp the structural defects and existing problems and demonstrate the benefit of clearly positioning the role of new techniques and methods, such as complex networks, in urban design and planning processes. Then, complex network-related land-use research will be further discussed, such as the application of determining the important nodes in urban land-use planning. This will be followed by the direct or indirect applications of complex network theory in land-use and revelations of the management of land-use for the identification of the key changed land-use types in land-use cover change (LUCC). Next, some of the latest research related to land-use, such as coevolution models and multilayer networks, will be reviewed. Finally, a summary of this article and future outlooks are presented.

\section{Literature Review Approach}

In this paper, the literature on the land-use and transport interaction and complex network theory is collected and reviewed through multiple channels. Academic databases such as Science Direct Journals, Scopus, Web of Science, and Google Scholar were used. The references and citation lists of some important papers in these fields were further searched. Combinations of the following searchable terms were used to find the relevant literature: land-use, complex network, land-use model, land-use and transport interaction, landscape connectivity, and multilayer network. The traditional literatures of the land-use and transport interaction research are not limited by date; however, the literature based on complex network theory is limited to the past 18 years (2001-2019). Since this review paper is the first step in discussing the application of complex network theory in land-use and transport interaction, it only focuses on some studies that have addressed the research gaps. The gaps have shown that urban traffic network growth and its impact on surrounding land-use, landscape connectivity properties, the identification of key changed land-use types, coevolution process, and multimodal-based studies need more concern. Theoretical studies that do not examine land-use and transport interaction or highlight the major limitations and complex network studies that emphasize physics more were excluded from the search results. A total of 69 articles for land-use and transport interaction and 75 complex networkrelated articles were chosen and analysed.

\section{The Traditional Land-Use and Transportation Interaction Models}

An urban system is a complex system composed of many subsystems. Land-use, transportation, and population are the most important subsystems, especially when considering the urban growth process, as they develop, prosper, and influence one another [34]. A wide range of approaches to model urban land-use and transportation have evolved. Many studies keenly approach the relationship between urban land development and transportation [24, 30, 33, 35, 36].

Theories on the urban land-use and traffic system have been proposed for a long time and have been prolific. Researchers have deeply discussed and shaped the relationships between urban land-use and traffic systems from varying perspectives. They believe that there are many kinds of interactions and interrelations that periodically affect and dynamically respond to one another. Urban land-use is the root source of urban traffic demand, which not only determines the source of urban traffic and transportation but also regulates the urban traffic structure and foundation from a macroscopic perspective. Different kinds of urban land-use require different urban traffic patterns. Hence, Silva and $\mathrm{Wu}$ [30] divide the urban growth models into five parts, including planning tasks, land-use/land-cover change, urban growth, transportation-related issues (the integrated model), impact assessment, and comprehensive projection. Hence, I will focus more on urban growth models, land-use models, and integrated models to clarify the research needs of complex network theory.

3.1. The Urban Growth Models. To measure the growth process of urban traffic networks, the research has concentrated on two aspects. The first is the modelling and simulation of urban growth, and the second is based on their true natural course. With more concentration on urban growth phenomena, some metropolitan growth forecasting and simulation models have been presented. The California Urban Futures Model (CUF) [37] provides a GIS-based urban growth model to illustrate the influence of realistic growth and development policies on the locations, patterns, and intensity changes of urban development. SLEUTH (Slope, Land-use, Exclusion, Urban extent, Transportation, and Hill shade) $[38,39]$ is a cellular automaton-based model. The related growth rules are predefined and applied spatially to the gridded city map. Thus, the behaviour of the CA model is controlled by related input data and different changing coefficients. UPlan [40] was configured as a GISbased and travel simulation integrated land-use planning tool and is applicable in a wide variety of rural, suburban, and urban areas. The attractiveness of landscape features (such as freeways and major roadways) and growth constraints are both considered [41]. Without question, urban population growth is one of the most important elements in almost every aspect of the urban growth process. From the perspective of economics and land-use, building density is determined by 
population density. Therefore, the ternary structure of urban form (roads, intersections and buildings) can be converted into a relationship between the road system and population density [42]. Other works mainly focus on the geometrical properties of urban traffic networks at a specific time point, as was previously recommended. However, for a real human complex system, with the growth of the urban population and living efficiency requirements, the urban traffic network is continuously experiencing expansion.

The abovementioned models describe the urban growth process from different perspectives. However, only a few works have focused on urban traffic network growth and its impact on land-use $[43,44]$. Thus, the research on the urban growth process, which is linked to the urban traffic network growth process and the basic thinking of complex network theory, needs further attention. Two elementary processes have been proposed to describe this process: densification and exploration. Densification is the process of "increase in the local density of roads around existing urban centers", and exploration refers to the fact that "new roads trigger the spatial evolution of the urbanization front" [44]. On this basis, Mohajeri and Gudmundsson [43] quantified the characteristics of Sheffield (England) and Khorramabad and Kerman (Iran) and examined the urban traffic network growth process using three methods: orientation, length, and Shannon-Gibbs entropy analyses.

3.2. The Land-Use Models. According to the review and classification of Rui [45], the urban land-use model has six parts. These great models have solid urban study backgrounds, and many credible references have been published previously. In spatial interaction models, land-use interactions are explained by factors that cause the concentration and spread of urban functions. Most of these models are based on gravity and demand models. The mathematical or statistical models are always merged with other models to attain a static or equilibrium status in the economic analysis. Sometimes, these models are referred to as macro- and microsimulation [46-49]. The expert models use land-use uncertainty to predict which land-use type is likely to occur at a certain point or area. These methods include Bayesian probability [5052], Artificial Intelligence (e.g., Artificial Neural Network) $[53,54]$, and the Markov models $[55,56]$. Cellular automata models $[46,57-62]$ are normally used to address the direct push and pull interactions between neighbouring land-uses, and based on the simple transition rules, bottom-up changing trends will emerge [63, 64]. Agent-based modelling [46, 65-67] and multiagent simulation [68-70] have also been considered.

In fact, the land-use models and the land-use and transport interaction models have many overlapping sections because, in most of the former models, traffic is the artery connecting different land parcels and the engine of local economic development, while in the latter models, land-use and transport are indispensable components. Human activity is the primary result of social and economic behaviour and is also a factor driving land-use change [71], and it should be linked to traffic flow to achieve the influence of local land-use. Then, we have the following research on the integrated model.
3.3. The Integrated Models. Urban geographers, traffic engineers, and urban planners have paid constant attention to the close interactions and complex relationships between urban traffic and land-use. Lowry's model of metropolis was the first attempt to implement urban land-use traffic feedback cycles in an operational model. It essentially integrated the residential location model and the retail employment location model in the forefront [72]. Lowry's model inspired a large number of increasingly complex modelling approaches. Here, I use Table 1 to show these existing integrated models. Table 1 is adapted from Wegener [33], in which already thoroughly discussed these related subsystems from the perspective of different change speed. In this paper, the elements like "Accessibility, Coevolution, Multimodal-based and Country or area applied" and more models were further considered and discussed.

An integrated model of residential and employment location in a metropolitan region (IMREL) is given by Anderstig and Mattsson [73], which not only considers the complex relationships between these subsystems but also further discusses their accessibility to the labour force. After that, a wide range of different approaches to model urban land-use and transportation have evolved in IRPUD $[33,74]$. Putman [75] presents the integrated transport and landuse package (ITLUP), the results of more than a decade of investigation, and theoretical and empirical analyses are described. The Leeds integrated land-use transport model (LILT) has been used to represent the relationships between transport costs and the spatial distribution of the population [76]. The Marcial Echenique and Partners' software package (MEPLAN) was used by Echenique, Flowerdew et al. [77] to "predict the effects (relative to a base case) of a common programme of land-use and transport policies or scenarios" (p.1) of Bilbao, Leeds and Dortmund. It almost discusses every urban subsystem and introduces new ideas on the test of the impacts of adding new roads and increasing the operating speeds of all mechanized modes. The integrated land-use, transportation, and environment modelling system (ILUTE) was proposed by Miller and Salvini [78], which represents a framework of the environmentally impacted, comprehensive, integrated land-use and transport model. After that, UrbanSim was proposed to address emerging needs and better coordinate the influence of traffic and land-use integration [79]. As a simulating model of spatial economic systems, the production, exchange, and consumption allocation system (PECAS) is proposed by Hunt [80]. In this research, the structure of the traffic network is less considered, but from the traffic flow point of view, the accessibility of the zone for activities is discussed. Both the Oregon transportation land-use model improvement program (TLUMIP) [81] and TRANUS integrated land-use and transport model [82-84] cover almost all subsystems and consider the accessibility of feedback, with the TRANUS model discussed the growth of the multimodal network. The transportation and environment strategy impact simulator (TRESIS) [85] is used to predict the impact of transport strategies, and to make recommendations, accessibility indices were discussed.

After further discussion of the concept of accessibility, a basic theoretical framework of the interactive design of 


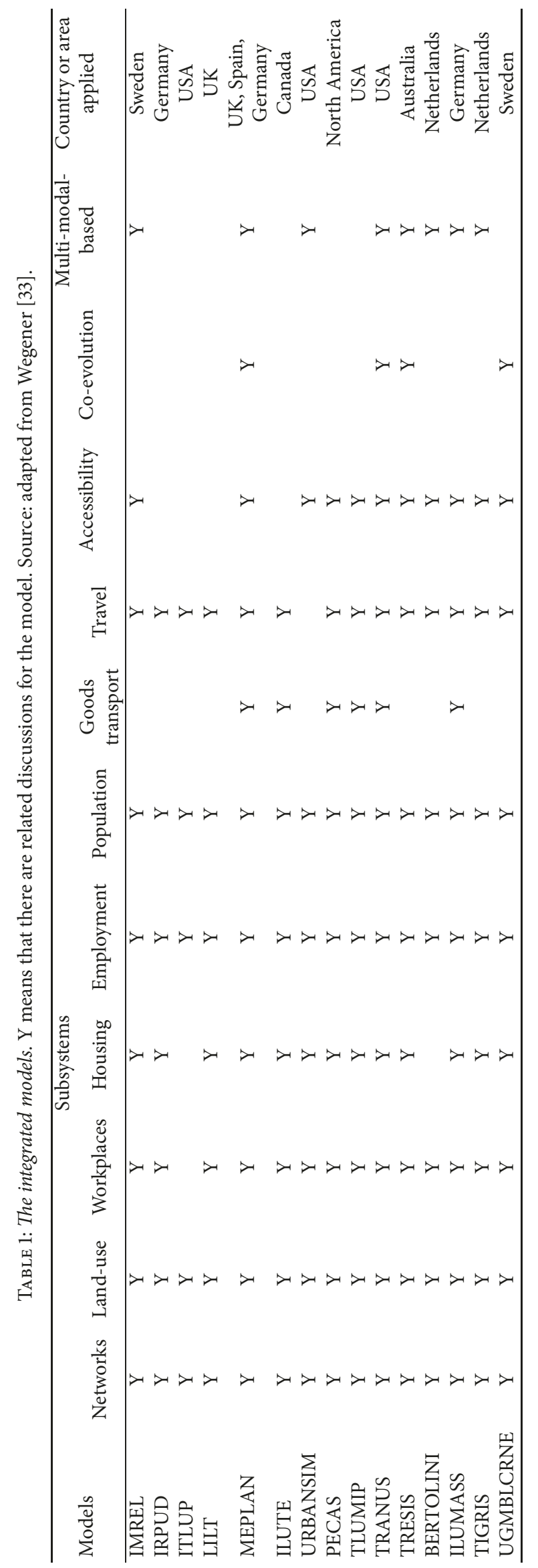


combined plans in the Netherlands (BERTOLINI) (we name this model using the name of the author) was proposed by Bertolini, Le Clercq et al. [86], who used the concept of accessibility and showed how this concept can be employed in the integration of traffic and land-use planning in an interactive plan-making process. Integrated land-use modelling and transportation system simulation (ILUMASS) is based on six interrelated work packages that include the microsimulation of changes in land-use (IRPUD), microsimulation of activity patterns and travel demand, microsimulation of traffic flows by dynamic traffic assignment, simulation of goods transport, simulation of goods transport and integration and coordination. It also expends effort toward the accessibility of jobs, shops, populations, and facilities to reflect spatial interactions. Transport infrastructure landuse (Dutch: Grondgebruik) interaction simulation (TIGRIS) [87] and its variation, TIGRIS-XL [88, 89], were proposed for the Netherlands, ignoring the goods transport but fully considering other subsystems. Later, Rui [45] proposed an urban growth model based on land-use changes and road network expansion (UGMBLCRNE) based on three types of agents (residential agents, developer agents and government agents), the traffic network growth process was explored, and accessibility was discussed. Only the MEPLAN, TRANUS, TRESIS, and UGMBLCRNE models considered the dynamic process of coevolution.

3.4. Existing Research Gaps. From the discussion of the studies in Section 3.3, it is obvious that these models all considered the traffic network, land-use, employment, population, and travel subsystems. Naturally, high-density urban landuse models require high-capacity public transportation and adaptation, while low-density urban land-use models result in a freeway traffic mode $[90,91]$. These classic studies have confirmed an integral feature of land-use and transportation. The actual operation level of a traffic system will in turn affect the urban spatial structures and urban development scales. Consequently, the operation level will affect the city landuse status, especially urban traffic accessibility, and play a decisive role in the spatial distribution of urban economic, commercial, and cultural activities [92]. Most of these models applied accessibility as their key point to reflect the spatial interactions between different subsystems.

However, some gaps were observed based on the literature review. First, from the opinion of urban growth models, only a few works have focused on urban traffic network growth and its impact on land-use. Secondly, from the point of land-use models, the measurement of traffic networks' influences, landscape connectivity properties and the identification of key changed land-use types to some extent are less considered. Thirdly, from the view of integrated models, only a few of them have considered the coevolution process and part of them have reflected different traffic modes. This fact poses challenges for our next research approach, and hopefully, these fundamental questions can be answered and the relationship between network structure and land-use can be clarified via complex network theories [93].

\section{The Complex Network Theory-Based Urban Land-Use and Transport Interaction Research}

The rudimentary concepts and content of complex network theory have already been thoroughly introduced in some previous articles $[10,94]$, and its related applications in urban traffic have been fully discussed [15]. From these experiences and cognitions, we can clearly see that the applications of complex network theory in land-use and transport interaction have certain phases and characteristics (Figure 1), and they were taken from graph theory and applied to land-use by Urban and Keitt [95]. The research on basic topology structures using basic graph theory came first. Then, these ideas were expanded to urban networks, and close attention was paid to node importance and network centrality, which led to protecting or attacking those important nodes and related research on multiple centrality assessment and kernel density estimation methods. Research branching from urban networks, such as landscape connectivity and the identification of key changed land-use types, have recently attracted scholars' attention. Network growth and multilayer networks have also been discussed, and these studies have extended the network coevolution models, connections between different land-use types and most of the related studies to a further state. Below, this paper will further discuss these particular topics, and some of this information is inherited from Ding, Ujang et al. [15] but from the perspective of land-use and transport interaction.

4.1. The Basic Idea of Urban Networks: Find the Important Nodes to Protect or Attack. Of primary importance is to find the important nodes in the initial context of a complex network [96], which has significant meaning not only in research of the basic structure and function of the urban network but also in urban land-use and ecological studies [95, 97]. Examples include finding the most valuable land parcel for construction or searching for critical land parcels to protect biodiversity, exploring the land parcel to efficiently restore the ecosystem with relatively lower human resources and material resources input, and even determining "which patches are most crucial to maintaining overall recruitment, flux, and traversability" [95].

The fundamental idea of complex network theory is that there are many complex systems in nature, and most of these systems can be quantitatively described by network methods. A representative complex network generally includes two important elements: nodes and links. Nodes represent those different individuals or areas of concentration in the real world, and links represent the connections between these nodes. These connections can be intuitively similar to those in a traffic network, where the intersections are connected by roads, or obscure, as in the identification process of key changed land-use types. The transfer relationship acts as the network connection.

Based on the network topology structure and weight on each link, we can use classic graph theory and a social network analysis method to analyse those critical indicators 


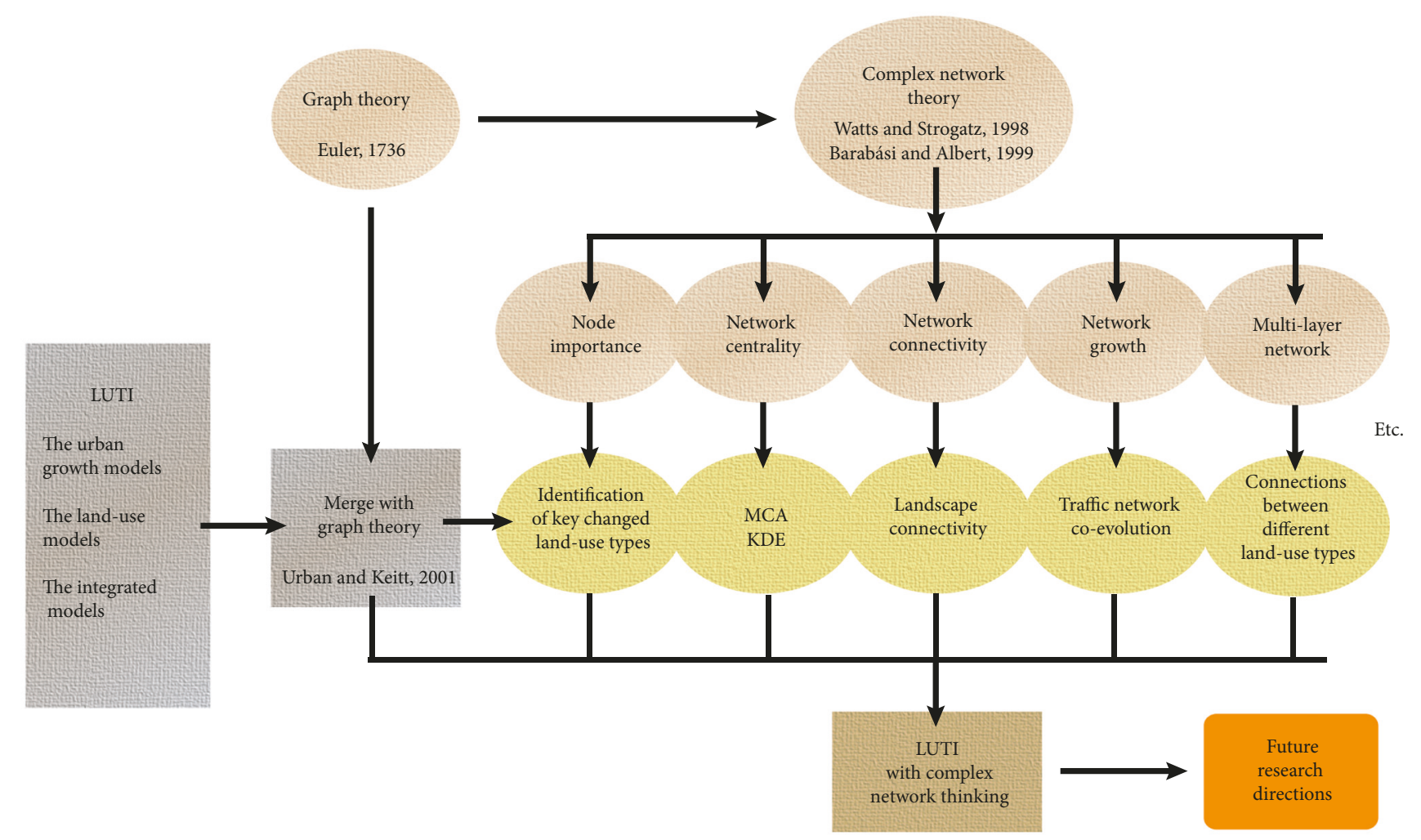

FIGURE 1: The framework for combining complex network theory with land-use and transport interaction.

of node importance. Centrality assessment is a fundamental concept in geographical network analysis and was introduced earlier in the context of social network research [98-100]. Indicators including degree centrality, betweenness centrality, and closeness centrality depict the importance of nodes in a network from different aspects, and the mathematic functions that these indicators can be referred to Ding, Ujang et al. [15]. Using these centrality assessments to determine those critical nodes, we can protect them from natural disasters and artificial attacks to increase the reliability of the whole network, and we can attack the weakest points to break down the entire network.

\subsection{The Multiple Centrality Assessment and Kernel Density} Estimation Approaches: Intuitionistic Connections. Here, this paper discusses intuitionistic connections that actually treat streets as links and intersections as nodes. This approach is also referred to as the primal approach [101]. For other network representation methods, one can refer to Ding, Ujang et al. [15]. Concern for the basic structure of the urban network will yield tremendous benefits in the long run for urban forms and land-use. This process, for now, is mainly based on the assessment and analysis of network centralities.

Recently, many other metrics have been proposed, such as the multiple centrality assessment (MCA) model and kernel density estimation (KDE) method introduced by Sergio Porta, Paolo Crucitti and Vito Latora. The complementary methods to the traditional methods, such as space syntax [102-104], specify a set of methods for measuring and quantifying the centralities of urban spatial networks as another technical perspective for urban planning and design [101, 105-110]. In-depth explanations and demonstrations of the KDE method can be found in [110]. Here, this paper will focus more on the properties of network centrality. During the past decade, Sergio Porta, Paolo Crucitti and Vito Latora have performed some real projects to illustrate these methods, considering Bologna [110] and Barcelona [109] within a similar research paradigm, in which they pointed out that in urban planning, the central urban arterials should be the core, compared to the borders and neighbourhoods. Initially, they plotted real urban situations as street networks. The KDE method was used to determine the lumps of these various types of economic activities. Following the analysis of the properties and calculation of these global indices of street centralities, the authors obtained a mixed map of urban economic activities and network centralities. Then, the interrelations emerged, and they were able make an assessment via correlation analysis, which examined the statistical properties of their probability distributions. It is relatively easy to further understand their relationships, as proposed by Liu, Wang et al. [111]. Scheurer, Curtis et al. [112] provided further elaboration on this concept. MCA's key assessment methods were applied to integrated landuse and traffic planning in the Perth metropolitan area in five different scenarios. These scenarios included the betweenness centrality variation of the scenario frequency boost, scenario light rail corridors, scenario middle ring centers, scenario fringe expansion, and scenario composite 
wishbone. Unfortunately, limitations were still encountered. Workshop discussion and expert experience were relied upon and only allowed for local optimum solutions. Sustainable accessibility's core concepts provide a spatial network analysis for multimodal urban transport systems [113]. Crucially, three cases were detailed. The potential of network centrality research is seen in its consideration of multiple factors for further exploration. Because Spearman's rho is normally used to assess whether the relationship between two variables can be better described by a monotonic function, Rui [45] has examined this relationship to further understand the impact of road network centralities on land-use categories. Urban Network Analysis, a toolbox based on the ArcGIS platform, was encoded by Sevtsuk and Mekonnen [93], in which buildings were taken into account as one more related map element in terms of the accessibility and centrality of spatial networks. Then, the authors comprehensively introduced this toolbox within the context of MCA. Most recently, the KDE method has been used to delimit urban commercial central districts by Yang, Zhu et al. [114], and they have shown that planar KDE and network KDE methods have limitations, and the commercial-intersection KDE method was proposed based on point-of-interest (POI) data.

\subsection{Landscape Connectivity: Obscure Connections. Complex} network theory in urban land-use is focused on landscape connectivity [95]. It is a relatively new concept, acting as an obscure representation method and cross-research based on graph theory. These habitat patches are the nodes of the landscape graph, while the links represent the functional connections between the nodes. Most of the links are generated if the cost of movement between two nodes is less than a given value (or a given probability). Habitat patch networks can be applied to quantify the impacts of management decisions on landscape connectivity $[95,115-$ 118]. Cheng, Bertolini et al. [119] stated that urban networks are made up of three basic types: morphology-oriented nodebased, density-based and function-oriented accessibilitybased. Land-use planners have a tendency to employ direct distance to measure spatial interaction while using density to measure the spatial concentration of social and economic activities. The resulting graph may be used to compute connectivity metrics at different structural levels, as Rayfield, Fortin et al. [29] defined. Four levels (the element level, the neighbourhood level, the component level and the network level), encompassing approximately 60 indicators, were used. These indicators should be user-friendly and provide robust estimates of a species' sensitivity to land-use changes, given its low data requirements compared to other models. Based on this research, Foltête, Girardet et al. [120] proposed a global framework for combining the needs arising from land-use planning with applications of landscape graphs, including the basic ideas of graph construction and graph computations to support prioritization. This approach may also support the improved connectivity of an ecological network to assess the potential impact of development on the ecological network by comparing different scenarios and determining the right spatial scale for measuring landscape connectivity.
These studies provide us with some inspiration for the application of complex network theory in urban land-use, such as using the node and link removal method to verify the change trend of landscape connectivity when some nodes are deleted [95, 115]. Zetterberg, Mörtberg et al. [121] applied the betweenness centrality method to calculate the betweenness value before and after the change of network structure. Other researchers used the node and link addition method to calculate the variation of landscape connectivity and the change of network structures when some planning nodes were added to the network [122]. It is also possible to propose a network structure-based plan that benefits biodiversity conservation $[123,124]$. The above methods, which focus more on the influence of the network structure change, are beyond the basic concepts of land-use and transport interaction models. In addition, these methods can obtain the information of some nodes badly in need of protection and development and may also be valuable for the guidance of the next detailed planning and optimization steps.

The identification of key changed land-use types in LUCC-related applications is quite rare but may be meaningful for planning practice, especially which can benefit the regional planning and local land-use change-related research [125-127]. The traditional methods mostly use remote sensing, field surveys, fixed-position observations, and measurements and document literature checks to detect and compare to the land-use cover change trends. These methods are based on the point of view of local land-use quantity change but lack a general point of view. They do not consider the land-use cover change process from the perspective of land-use and do not discuss the dynamic change in landuse structure [126]. The complex network method here is different and improved from the landscape connectivity to land-use change-related research via the aggregation of landuse types by an adjacency matrix. Although the complex network method also compares the change in different landuse types, it uses graph theory to analyse the related transfer matrix to determine the transformations between different land-use types from the system point view to distinguish key changes in land-use types in land-use cover change [125]. Thus, this method can be used to assess the stability of a land-use system. However, this method faces difficulty in analysing the specific reason and nature of a land parcel change from the microscopic angle; this aspect is a weakness that needs further improvement. Nevertheless, this method still contributes a new way of thinking and exploring, such as from a microscopic perspective to obtain a regional or local evolution matrix based on a timeline, using the following two methods-coevolution and multilayer network theory-to study the law of transformation and the influence of network structures in different timelines.

4.4. The Coevolution Theory: A New Integrated Way of Thinking. Kii, Nakanishi et al. [35] discussed directions for the further study of land-use and transport interaction and stated that "more flexible, more complex, more intensive modelling" and "local and global land-use and transport interaction models and coevolution toward sustainability science" provide us with future prospects for land-use and 
transport interaction models and involve some complexity science-related content. Some related research has noted the importance and advantages of coevolution models between urban land-use and urban traffic networks. This research direction is based on and extends complex network theory. It is a demand prediction method and impacts analysis based on urban land-use and traffic demand (in some aspects such as human activity). It is a new direction that may be used to explore the interrelationships between different elements of the complex urban system. This research not only mathematically describes the interior of this complex system but also simulates the immeasurable parts of initial land-use models; it also integrates the policy impact analysis and social and geographical context.

Levinson, Xie et al. [128] stated that population and employment accessibility are the primary factors taken into account in system users' location decisions. These users include workers, businesses, and households. Network effects and some macro- and microeconomic policies, such as coevolution processes and general models, were proposed by Levinson, Yerra and Xie et al. [129-134]. These models incorporate network structure, travel demand, revenue, cost, and investment models as well as accessibility and land-use models. A paradigm was formed by using these various models to simulate the changing trends and interrelations between the land-use and traffic system, followed by sensitivity analysis, which considers the influence of the changing variables [135]. Interest in general bilevel programming has grown [136], and CA models [137] have helped to describe this phenomenon; further, the interrelationships among population, roads, vehicle ownership, and land development were further analysed [138]. Levinson and Xie, examining the coevolution model of 19th and 20th century London, demonstrated that population distribution and network density are positively correlated. A simulation model was then used to better fit the empirical evidence. Essentially, evolution is an iterative process of interaction, investment, and divestment. The spontaneous growth and decline of surface traffic networks show properties of selforganization [32, 34, 132, 133]. Other related analyses were made by Ding, Ujang et al. [15].

From the studies above, we can see that coevolutionrelated research is a part of integrated research, although most of the initial integrated research, including MCA-related research, is based on the equilibrium situation, coevolution research is dynamic and variational, and its estimation precision is limited by the source data. With the prosperous use of big data research methods, these datasets can be obtained from cell phone data or other comprehensive traffic GPS data with higher accuracy ratings. Then, more accurate OD data can be gained, and the consideration of this coevolution method will focus more on the merging of the change trends of population distribution, traffic network structure, urban land-use and even the economic center [139]. With the clear explanation and representation of these internal relationships by the single-layer and multilayer network theory of these different traffic modes (rail, bus, private car, motorcycle, bicycle, etc.), we can obtain more accurate coevolution models.
4.5. Multilayer Networks: A Novel Method to Measure Interactions. Recently, many modern physics and urban transportation studies have focused on multilayer networks. As the missing links in the research of urban land-use, researchers normally pay attention to a land parcel and its relationship with surrounding land parcels, disregarding the catalysis of one land-use type to the district or whole region. Researchers may also ignore the influence of different land-use types (the interactions between different network layers). We need to understand their research progress and research potential to approach urban land-use issues.

A general multilayer model was proposed by Kurant and Thiran [140] to better address the description and analysis of multilayer networks and examine the differences between multilayer network representations and real-world networks. They studied three traffic networks, finding that even a small error in the multilayer network could lead to the structural disaster in the general network. The relationships among degree, betweenness and real loads were also examined. In contrast to conventional belief, the correlations among the three factors remained unapparent. As reviewed by Ding, Ujang et al. [15], Buldyrev, Parshani et al. [141] later showed that electrical blackouts resulted in the cascading failure of the communication network and power stations in Italy. This milestone further enhanced the measurement of interactions in layered networks. The authors thus determined the critical percolation threshold, and this threshold may be larger than the equivalent threshold of a single-layer network of the same size. Additionally, Albert, Sergio et al. [142] introduced a standardized model to simulate the elements navigating those networks and analysed congestion in multilayer transportation networks. A model of traffic dynamics crucially revealed a transition at the onset of cooperation between layered networks, as proposed by $\mathrm{Gu}$, Zou et al. [143], who introduced the use of the cooperation strength between different layers to describe the relationships among coupling networks. Additionally, when coupling different modes, speed ratios, network accessibility, mobility, and layer behaviours were examined [142, 144-146]. As Ding, Ujang et al. [147] illustrated, users' behaviours will change dramatically through the coevolution process when the cooperation between different traffic layers works as a changeable parameter. The interrelationship and cooperation strength of different traffic layers must be considered in any investigation of certain aspects of multilayer networks to optimize urban forms $[146,148]$. Based on the study of Kuala Lumpur, Ding, Ujang et al. [149] found that when the upper-layer network grows from a simple form to a more intricate form, the indicators such as network diameter, network accessibility and the average shortest path length of multilayer networks were changed dramatically, which indicated that urban traffic networks were optimized.

Although the related research still rests on the topological, evolution, vulnerability, and information transfer process of multilayer networks, the effect of these aspects on landscape networks is obvious. Here, I enumerate some passable applications. For example, the connections between different landuse types can be described in a transfer matrix, but it is relatively difficult to describe their micro and local evolution 
and cohesion. Multilayer networks allow us to explore the relational closeness and connection mode of relationships among different network layers, mining some still unclear information from traditional land-use studies. Such networks may also be used in the study of local land-use change, such as the influence of the development of subway routes on land and house prices of the whole area or the impact of regional planning and the diffusion process of these changes and influences, as well as their range of influence, which also includes the connection between the effects of different network layers on land transportation accessibility.

\section{Conclusions and Future Research Directions}

This paper focuses on the application of complex network theory in urban traffic network and land-use based researches and practices, to fill the gaps which are existing in recent land-use and transport interaction studies. According to the literature review, it is clear that the application of complex network theory in land-use and transport interaction studies has many advantages. As the study of node importance is efficient for the identification of the important nodes to protect or attack. The multiple centrality assessment and kernel density estimation approaches can be used to represent the intuitionistic connections of urban traffic networks and surrounding land-uses; with different indicators, these quantitative measurement methods can be easily applied. It can be used to verify the change trend and to calculate the variation of landscape connectivity, the connection between different land-use parcels can be quantitatively discussed. It also can applied to the identification of key changed landuse types in land-use cover change; with this technique, the planners and decision makers can grasp these specific situations comprehensively. The coevolution theory can be treated as an integrated way to discuss the relationships between urban traffic networks and land-uses. The multilayer networks based analysis is a novel method to measure interactions between urban traffic networks and land-uses.

However, for the further application of a complex network in land-use and transport interaction studies, the following points require additional attention.

The application framework and methodological perspective of applied complex network theory in urban planning have still not been established, and the integration between traffic networks and surrounding areas, such as land-use parcels, building, and even population distribution, needs to be explored further. Multiobjectives, multilayer network methods (pedestrians, vehicles, trains, spatial traffic networks, land-use, buildings, etc.), and modularity design technology require more attention in the near-future urban planning process, especially for metropolis planning. Combined with node importance, network centrality, and the influence of a traffic network structure change, these novel quantitative study methods can be applied to modern humanities/geography research, for instance, the sense of place (place attachment, place identity, and place dependence) [150-153], to assess the user's sense and behaviour change before and after the network structure alteration.
The differences and connections between urban and rural area spatial networks warrant further discussion, which will benefit us not only in distinguishing them but also, more importantly, from general sense in assessing and designing different levels of spatial networks. Particularly, a user-friendly Graphical User Interface design in a Geographic Information System design environment is beneficial for urban designers' design processes and implementation. A complete urban spatial network assessment framework should be established as soon as possible, which can introduce these physical ideas simply and clearly to urban scholars and provide a systematic spatial quantitative approach to urban studies.

Some novel concepts of physics have rarely been imported into urban land-use, such as network robustness and vulnerability, but they obviously have great research significance. Urban and Keitt [95] proposed some basic ideas of the percolation threshold characteristic of raster lattices under the addition of nodes and edges or removal methods but did not consider their changing trends under complexity thinking. Interesting and challenging questions include how to effectively protect important nodes to improve the dependability of networks, lower costs to increase the landscape connectivity of the whole region and attack these vulnerable spots to suppress some incompatible development trend of land-use. Network robustness and vulnerability are confined not only to physical concepts but also to the functions applied to urban land-use planning. Other concepts, such as network controllability $[154,155]$ and resilience [156], are starting to attract attention. These new research directions have strong research potential, especially for their use in urban studies.

Effort should be made to clearly identify the importance of nodes or edges in single-layer and multilayer networks. Although many node indices have been proposed, most of them do not comprehensively consider complex urban properties. For example, some land-use parcels are critical to the general urban network within the consideration of economic contribution, population attraction, etc., but with the simplicity of unweighted graph, they show no difference from common nodes, which makes the assessment become less accurate.

The research on coevolution models and multilayer network models remains somewhat superficial, as mentioned in Sections 4.4 and 4.5, and the combination of coevolution models and multilayer network models with land-use applications is relatively rare. While research in this area is strongly forward-looking, as with previous city models, such research lacks a systematic and comprehensive economic description and combination with urban economic theory.

Many urban networks and land-use research focuses on traffic network accessibility and its impact on land-use under the initial context of urban studies. However, it is still unclear what will happen within the context of complex network theory. Can we thoroughly measure the influence of network structure change on regional accessibility, based on further studies of the conventional "person-based", "location-based", and "infrastructure-based" measures [24]? In this regard, the accessibility of multilayer networks has been tested by some critical approaches, but is lacking in the combination 
of accessibility and network optimization; hence, in the next few years, I believe that researchers in related fields will have a greater interest in taking this direction.

Exactly as Bergsten and Zetterberg [157] described, land fragmentation is not considered enough in municipal planning and implementation. They mentioned that none of the interviewed practitioners had used systematic methods to assess landscape connectivity. In addition, these systematic models based on complex network theory in recent urban planning paradigms are not strongly evident, predominantly because of the requirement of knowledge of modern physics, mathematics, and statistics, which most traditional urban planners and designers are short of.

\section{Conflicts of Interest}

The author declares that they have no conflicts of interest.

\section{Acknowledgments}

This study is funded by "Theoretical Innovation Project of Guizhou Province (Joint Project), Guizhou Provincial Federation of Social Sciences (GZLCLH-2019-009)" and "Talent Introduction Research Project of Guizhou University of Finance and Economics (no. 2019YJ003)”.

\section{References}

[1] A. Chatterjee, M. Manohar, and G. Ramadurai, "Statistical analysis of bus networks in India," PLOS ONE, Article ID e0168478, pp. 11-12, 2016.

[2] M. Kii, K. Akimoto, and K. Doi, "Random-growth urban model with geographical fitness," Physica A: Statistical Mechanics and its Applications, vol. 391, no. 23, pp. 5960-5970, 2012.

[3] K. Kocur-Bera, "Scale-free network theory in studying the structure of the road network in Poland," PROMET-Traffic \& Transportation, vol. 26, no. 3, pp. 235-242, 2014.

[4] H. Samaniego and M. E. Moses, "Cities as organisms: allometric scaling of urban road networks," Journal of Transport and LandUse, vol. 1, no. 1, pp. 21-39, 2008.

[5] C. Song, T. Koren, P. Wang, and A.-L. Barabási, "Modelling the scaling properties of human mobility," Nature Physics, vol. 6, no. 10, pp. 818-823, 2010.

[6] D. J. Watts and S. H. Strogatz, "Collective dynamics of "smallworld” networks," Nature, vol. 393, no. 6684, pp. 440-442, 1998.

[7] A. Barabasi and R. Albert, "Emergence of scaling in random networks," Science, vol. 286, no. 5439, pp. 509-512, 1999.

[8] A.-L. Barabási, R. Albert, and H. Jeong, "Scale-free characteristics of random networks: the topology of the world-wide web," Physica A: Statistical Mechanics and its Applications, vol. 281, no. 1, pp. 69-77, 2000.

[9] J. G. Restrepo, E. Ott, and B. R. Hunt, "Characterizing the dynamical importance of network nodes and links," Physical Review Letters, vol. 97, no. 9, article 094102, 2006.

[10] R. Albert and A.-L Barabási, "Statistical mechanics of complex networks," Reviews of Modern Physics, vol. 74, no. 1, article 47, 2002.

[11] M. E. J. Newman and M. Girvan, "Finding and evaluating community structure in networks," Physical Review E: Statistical, Nonlinear, and Soft Matter Physics, vol. 69, no. 2, article 026113, 2004.
[12] R. Albert, H. Jeong, and A.-L. Barabási, "Error and attack tolerance of complex networks," Nature, vol. 406, no. 6794, pp. 378-382, 2000.

[13] S. Boccaletti, G. Bianconi, R. Criado et al., "The structure and dynamics of multilayer networks," Physics Reports, vol. 544, no. 1, pp. 1-122, 2014.

[14] R. Ding, N. Ujang, H. B. Hamid, and J. Wu, "Complex network theory applied to the growth of Kuala Lumpur's public urban rail transit network," PLOS ONE, vol. 10, no. 10, Article ID e0139961, 2015.

[15] R. Ding, N. Ujang, H. B. Hamid et al., "Application of complex networks theory in urban traffic network researches," Networks and Spatial Economics, pp. 1-37, 2019.

[16] P. Erdős and A. Rényi, "On the evolution of random graphs," Publications of the Mathematical Institute of the Hungarian Academy of Sciences, vol. 5, no. 17-61, article 43, 1960.

[17] M. Barthélemy, “Spatial networks," Physics Reports, vol. 499, no. 1-3, pp. 1-101, 2011.

[18] A. Doménech, "A topological phase transition between smallworlds and fractal scaling in urban railway transportation networks?" Physica A: Statistical Mechanics and its Applications, vol. 388, no. 21, pp. 4658-4668, 2009.

[19] P. Kaluza, A. Kölzsch, M. T. Gastner, and B. Blasius, "The complex network of global cargo ship movements," Journal of the Royal Society Interface, vol. 7, no. 48, pp. 1093-1103, 2010.

[20] P. Sen, S. Dasgupta, A. Chatterjee, P. A. Sreeram, G. Mukherjee, and S. S. Manna, "Small-world properties of the Indian railway network," Physical Review E: Statistical, Nonlinear, and Soft Matter Physics, vol. 67, no. 3, article 036106, 2003.

[21] C. Andersson, A. Hellervik, K. Lindgren, A. Hagson, and J. Tornberg, "Urban economy as a scale-free network," Physical Review E: Statistical, Nonlinear, and Soft Matter Physics, vol. 68, no. 3, article 036124, 2003.

[22] B. Jiang and C. Claramunt, "Topological analysis of urban street networks," Environment and Planning B: Planning and Design, vol. 31, no. 1, pp. 151-162, 2004.

[23] S. Porta, P. Crucitti, and V. Latora, "The network analysis of urban streets: a dual approach," Physica A: Statistical Mechanics and its Applications, vol. 369, no. 2, pp. 853-866, 2006.

[24] R. A. Acheampong and E. A. Silva, "Land use-transport interaction modeling: a review of the literature and future research directions," Journal of Transport and Land Use, vol. 8, no. 3, pp. 11-38, 2015.

[25] J. S. Chang, "Models of the relationship between transport and land-use: a review," Transport Reviews, vol. 26, no. 3, pp. 325350, 2006.

[26] S. Derrible and C. Kennedy, "Applications of graph theory and network science to transit network design," Transport Reviews, vol. 31, no. 4, pp. 495-519, 2011.

[27] C. Ducruet and L. Beauguitte, "Spatial science and network science: review and outcomes of a complex relationship," Networks and Spatial Economics, vol. 14, no. 3-4, pp. 297-316, 2014.

[28] Z. Gao, X. Zhao, H.-j. Huang, and B. Mao, "Research on problems related to complex networks and urban traffic systems," Journal of Transportation Systems Engineering and Information Technology, vol. 6, no. 3, pp. 41-47, 2006.

[29] B. Rayfield, M.-J. Fortin, and A. Fall, "Connectivity for conservation: a framework to classify network measures," Ecology, vol. 92, no. 4, pp. 847-858, 2011.

[30] E. Silva and N. Wu, "Surveying models in urban land studies," Journal of Planning Literature, vol. 27, no. 2, pp. 139-152, 2012. 
[31] P. Waddell, "Integrated land use and transportation planning and modelling: addressing challenges in research and practice," Transport Reviews, vol. 31, no. 2, pp. 209-229, 2011.

[32] F. Xie and D. Levinson, "Modeling the growth of transportation networks: a comprehensive review," Networks and Spatial Economics, vol. 9, no. 3, pp. 291-307, 2009.

[33] M. Wegener, "Overview of land use transport models," Handbook of Transport Geography and Spatial Systems, vol. 5, pp. 127146, 2004.

[34] D. Levinson, "Density and dispersion: the co-development of land use and rail in London," Journal of Economic Geography, vol. 8, no. 1, pp. 55-77, 2008.

[35] M. Kii, H. Nakanishi, K. Nakamura, and K. Doi, "Transportation and spatial development: an overview and a future direction," Transport Policy, vol. 49, pp. 148-158, 2016.

[36] M. Wegener, "Operational urban models state of the art," Journal of the American Planning Association, vol. 60, no. 1, pp. 17-29, 1994.

[37] J. Landis, "CUF, CUF II, and CURBA: a family of spatially explicit urban growth and land-use policy simulation models," in Planning Support Systems, Integrating Geographic Information Systems, Models and Visualization Tools, R. Brail and R. Klosterman, Eds., pp. 157-200, ESRI Press, Redlands, Calif, USA, 2001.

[38] C. A. Jantz, S. J. Goetz, D. Donato, and P. Claggett, “Designing and implementing a regional urban modeling system using the SLEUTH cellular urban model," Computers, Environment and Urban Systems, vol. 34, no. 1, pp. 1-16, 2010.

[39] E. A. Silva and K. C. Clarke, "Calibration of the SLEUTH urban growth model for Lisbon and Porto, Portugal," Computers, Environment and Urban Systems, vol. 26, no. 6, pp. 525-552, 2002.

[40] R. A. Johnston, D. R. Shabazian, and S. Gao, "UPlan: a versatile urban growth model for transportation planning," Transportation Research Record, vol. 1831, pp. 202-209, 2003.

[41] W. T. Walker, S. Gao, and R. A. Johnston, "UPlan: Geographic information system as framework for integrated land use planning model," Transportation Research Record: Journal of the Transportation Research Board, vol. 1994, pp. 117-127, 2007.

[42] F. Zhao, J. Wu, H. Sun, Z. Gao, and R. Liu, "Population-driven urban road evolution dynamic model," Networks and Spatial Economics, pp. 1-22, 2015.

[43] N. Mohajeri and A. Gudmundsson, "The evolution and complexity of urban street networks," Geographical Analysis, vol. 46, no. 4, pp. 345-367, 2014.

[44] E. Strano, V. Nicosia, V. Latora, S. Porta, and M. Barthélemy, "Elementary processes governing the evolution of road networks," Scientific Reports, vol. 2, 2012.

[45] Y. Rui, Urban Growth Modeling Based on Land-Use Changes and Road Network Expansion [Ph.D. thesis], KTH Royal Institute of Technology, Stockholm, Sweden, 2013.

[46] M. Batty, Cities and Complexity: Understanding Cities with Cellular Automata, Agent-Based Models, and Fractals, The MIT press, 2007.

[47] M. Batty, Urban Modeling, International Encyclopedia of Human Geography, Elsevier, Oxford, UK, 2009.

[48] M. Batty, The New Science of Cities, The MIT Press, 2013.

[49] M. Fujita and H. Ogawa, "Multiple equilibria and structural transition of non-monocentric urban configurations," Regional Science \& Urban Economics, vol. 12, no. 2, pp. 161-196, 1982.

[50] C. M. De Almeida, A. M. Vieira Monteiro, G. Câmara et al., "GIS and remote sensing as tools for the simulation of urban land-use change," International Journal of Remote Sensing, vol. 26, no. 4, pp. 759-774, 2005.

[51] R. Aspinall and N. Veitch, "Habitat mapping from satellite imagery and wildlife survey data using a Bayesian modeling procedure in a GIS," Photogrammetric Engineering and Remote Sensing, vol. 59, no. 4, pp. 537-543, 1993.

[52] C. H. Tom and L. D. Miller, "An automated land-use mapping comparison of the Bayesian maximum likelihood and linear discriminant analysis algorithms," Photogrammetric Engineering and Remote Sensing, vol. 50, no. 2, pp. 193-207, 1984.

[53] R. Arasteh, R. A. Abbaspour, and A. Salmanmahiny, "A modeling approach to path dependent and non-path dependent urban allocation in a rapidly growing region," Sustainable Cities and Society, vol. 44, pp. 378-394, 2019.

[54] K. Islam, M. F. Rahman, and M. Jashimuddin, "Modeling land use change using Cellular Automata and Artificial Neural Network: The case of Chunati Wildlife Sanctuary, Bangladesh," Ecological Indicators, vol. 88, pp. 439-453, 2018.

[55] M. R. Muller and J. Middleton, "A Markov model of landuse change dynamics in the Niagara Region, Ontario, Canada," Landscape Ecology, vol. 9, no. 2, pp. 151-157, 1994.

[56] Q. Weng, "Land use change analysis in the Zhujiang Delta of China using satellite remote sensing, GIS and stochastic modelling," Journal of Environmental Management, vol. 64, no. 3, pp. 273-284, 2002.

[57] M. Batty, H. Couclelis, and M. Eichen, "Urban systems as cellular automata," Environment and Planning B: Planning and Design, vol. 24, no. 2, pp. 159-164, 1997.

[58] P. M. Torrens and D. O'Sullivan, "Cellular automata and urban simulation: where do we go from here?" Environment and Planning B: Planning and Design, vol. 28, no. 2, pp. 163-168, 2001.

[59] J. Von Neumann and O. Morgenstern, Theory of Games and Economic Behavior, Princeton University Press, 2007.

[60] R. White and G. Engelen, "Cellular automata and fractal urban form: a cellular modelling approach to the evolution of urban land-use patterns," Environment and Planning A, vol. 25, no. 8, pp. 1175-1199, 1993.

[61] S. Wolfram, Theory and Applications of Cellular Automata, vol. 1, World Scientific, Singapore, 1986.

[62] S. Wolfram, Cellular Automata and Complexity: Collected Papers, vol. 1, Addison-Wesley Reading, 1994.

[63] P. H. Verburg, T. C. M. de Nijs, J. R. van Eck, H. Visser, and K. de Jong, "A method to analyse neighbourhood characteristics of land use patterns," Computers, Environment and Urban Systems, vol. 28, no. 6, pp. 667-690, 2004.

[64] P. H. Verburg, J. R. Ritsema van Eck, T. C. M. de Nijs, M. J. Dijst, and P. Schot, "Determinants of land-use change patterns in the Netherlands," Environment and Planning B: Planning \& Design, vol. 31, no. 1, pp. 125-150, 2004.

[65] X. Chen and F. B. Zhan, "Agent-based modelling and simulation of urban evacuation: relative effectiveness of simultaneous and staged evacuation strategies," Journal of the Operational Research Society, vol. 59, no. 1, pp. 25-33, 2008.

[66] R. B. Matthews, N. G. Gilbert, A. Roach, J. G. Polhill, and N. M. Gotts, "Agent-based land-use models: a review of applications," Landscape Ecology, vol. 22, no. 10, pp. 1447-1459, 2007.

[67] Y. Xie, M. Batty, and K. Zhao, "Simulating emergent urban form using agent-based modeling: Desakota in the SuzhouWuxian Region in China," Annals of the Association of American Geographers, vol. 97, no. 3, pp. 477-495, 2007. 
[68] J. Ferber, Multi-Agent Systems: An Introduction to Distributed Artificial Intelligence, vol. 1, Addison-Wesley Reading, 1999.

[69] N. Minar, R. Burkhart, C. Langton, and M. Askenazi, The Swarm Simulation System: A Toolkit for Building Multi-Agent Simulations, 1996.

[70] D. C. Parker, S. M. Manson, M. A. Janssen, M. J. Hoffmann, and P. Deadman, "Multi-agent systems for the simulation of landuse and land-cover change: a review," Annals of the Association of American Geographers, vol. 93, no. 2, pp. 314-337, 2003.

[71] E. F. Lambin, H. J. Geist, and E. Lepers, "Dynamics of land-use and land-cover change in tropical regions," Annual Review of Environment and Resources, vol. 28, no. 1, pp. 205-241, 2003.

[72] J. P. Crecine, A Dynamic Model of Urban Structure: DTIC Document, RAND Corporation, 1968.

[73] C. Anderstig and L.-G. Mattsson, "An integrated model of residential and employment location in a metropolitan region," Papers in Regional Science, vol. 70, no. 2, pp. 167-184, 1991.

[74] M. Wegener, The IRPUD Model: Overview, Website of the Institute of Spatial Planning, University of Dortmund, 1998.

[75] S. Putman, "Integrated urban models: policy analysis of transportation and land-use, london: pion," Transportation, vol. 3, no. 3, pp. 193-224, 1983.

[76] R. L. Mackett, Leeds Integrated Land-Use Transport Model (LILT), TRRL Supplementary Report (Transport and Road Research Laboratory, Great Britain, UK, 1983.

[77] M. H. Echenique, A. D. J. Flowerdew, J. D. Hunt et al., "The Meplan models of bilbao, Leeds and Dortmund: Foreign summaries," Transport Reviews, vol. 10, no. 4, pp. 309-322, 1990.

[78] E. J. Miller and P. A. Salvini, “The integrated land-use, transportation, environment (ILUTE) microsimulation modelling system: description and current status," Travel Behaviour Research: The Leading Edge, pp. 711-724, 2001.

[79] P. Waddell, A. Borning, M. Noth, N. Freier, M. Becke, and G. Ulfarsson, "Microsimulation of urban development and location choices: design and implementation of UrbanSim," Networks and Spatial Economics, vol. 3, no. 1, pp. 43-67, 2003.

[80] J. D. Hunt, Design and Application of the Pecas Land-Use Modelling System, 2003.

[81] T. Weidner, R. Donnelly, J. Freedman, J. Abraham, and J. Hunt, "TLUMIP-transport land-use model in portlandcurrent state," Stadt Region Land, vol. 81, pp. 91-102, 2006.

[82] T. De La Barra, Integrated Land-Use and Transport Modelling: Decision Chains and Hierarchies, 1989.

[83] T. De La Barra, "Integrated land-use and transport modeling: the TRANUS experience," in Planning Support Systems: Integrating Geographic Information Systems, Models and Visualization Tools, R. K. Brail and R. E. Klosterman, Eds., 156, p. 129, ESRI Press, Redlands, Calif, USA, 2001.

[84] T. De La Barra, B. Perez, and N. Vera, "TRANUS-J: putting large models into small computers," Environment and Planning B: Planning and Design, vol. 11, no. 1, pp. 87-101, 1984.

[85] D. A. Hensher and T. Ton, "TRESIS: A transportation, land use and environmental strategy impact simulator for urban areas," Transportation, vol. 29, no. 4, pp. 439-457, 2002.

[86] L. Bertolini, F. le Clercq, and L. Kapoen, "Sustainable accessibility: a conceptual framework to integrate transport and land use plan-making. Two test-applications in the Netherlands and a reflection on the way forward," Transport Policy, vol. 12, no. 3, pp. 207-220, 2005.

[87] P. Eradus, A. Schoemakers, and T. Van Der Hoorn, "Four applications of the TIGRIS model in the Netherlands," Journal of Transport Geography, vol. 10, no. 2, pp. 111-121, 2002.
[88] B. Zondag, M. de Bok, K. T. Geurs, and E. Molenwijk, "Accessibility modeling and evaluation: The TIGRIS XL land-use and transport interaction model for the Netherlands," Computers, Environment and Urban Systems, vol. 49, pp. 115-125, 2015.

[89] B. Zondag and G. de Jong, "The development of the TIGRIS XL model: A bottom-up approach to transport, land-use and the economy," Research in Transportation Economics, vol. 31, no. 1, pp. 55-62, 2011.

[90] D. Qu, W. Wang, and D. Wang, "On urban land-use traffic planning system," Urban Planning Review, vol. 6, article 008, 1999.

[91] L. D. Z. A. W. Zongxin, "Urban land-use and the sustainable development of urban transport," China Population, Resources and Environment, vol. 4, article 008, 1999.

[92] X. Yan and J. Mao, "The mutual relationship between urban transport system and land use in highly-densely developed cities: a case study of Guangzhou," Acta Geographica Sinica, vol. 59, no. 5, pp. 643-652, 2004.

[93] A. Sevtsuk and M. Mekonnen, "Urban network analysis," Revue Internationale De Géomatique-n, pp. 287-305, 2012.

[94] M. Newman, A.-L. Barabasi, and D. J. Watts, The Structure and Dynamics of Networks, Princeton University Press, New Jersey, NJ, USA, 2011.

[95] D. Urban and T. Keitt, "Landscape connectivity: a graphtheoretic perspective," Ecology, vol. 82, no. 5, pp. 1205-1218, 2001.

[96] X. Ren and L. Lü, "Review of ranking nodes in complex networks," Chinese Journal, vol. 59, no. 13, article 1175, 2014.

[97] Y. Huang and T.-J. Liao, "An integrating approach of cellular automata and ecological network to predict the impact of landuse change on connectivity," Ecological Indicators, vol. 98, pp. 149-157, 2019.

[98] H. E. Bracey, "A rural component of centrality applied to six southern counties in the United Kingdom," Economic Geography, vol. 32, no. 1, pp. 38-50, 1956.

[99] L. C. Freeman, "A set of measures of centrality based on betweenness," Sociometry, vol. 40, no. 1, pp. 35-41, 1977.

[100] A. E. Smailes, "The urban mesh of england and wales," Transactions and Papers (Institute of British Geographers), vol. 11, pp. 87-101, 1946.

[101] S. Porta, P. Crucitti, and V. Latora, "The network analysis of urban streets: a primal approach," Environment and Planning B: Planning and Design, vol. 33, no. 5, pp. 705-725, 2006.

[102] S. Bafna, "Space syntax: a brief introduction to its logic and analytical techniques," Environment and Behavior, vol. 35, no. 1, pp. 17-29, 2003.

[103] B. Hillier, A. Leaman, P. Stansall, and M. Bedford, "Space syntax," Environment and Planning B: Planning and Design, vol. 3, no. 2, pp. 147-185, 1976.

[104] B. Jiang and C. Claramunt, "Integration of space syntax into GIS: new perspectives for urban morphology," Transactions in GIS, vol. 6, no. 3, pp. 295-309, 2002.

[105] P. Crucitti, V. Latora, and S. Porta, "Centrality in networks of urban streets," Chaos: An Interdisciplinary Journal of Nonlinear Science, vol. 16, no. 1, article 015113, 2006.

[106] V. Latora and M. Marchiori, "Economic small-world behavior in weighted networks," The European Physical Journal B, vol. 32, no. 2, pp. 249-263, 2003.

[107] S. Porta, P. Crucitti, and V. Latora, "Multiple centrality assessment in Parma: a network analysis of paths and open spaces," Urban Design International, vol. 13, no. 1, pp. 41-50, 2008. 
[108] S. Porta and V. Latora, "Multiple centrality assessment: Mapping centrality in networks of urban spaces," Urban Sustainability through Environmental Design: Approaches to Time-People-Place Responsive Urban Spaces, pp. 101-105, 2007.

[109] S. Porta, V. Latora, F. Wang et al., "Street centrality and the location of economic activities in Barcelona," Urban Studies, vol. 49, no. 7, pp. 1471-1488, 2011.

[110] S. Porta, E. Strano, V. Iacoviello et al., "Street centrality and densities of retail and services in Bologna, Italy," Environment and Planning B: Planning and Design, vol. 36, no. 3, pp. 450465, 2009.

[111] Y. Liu, H. Wang, L. Jiao et al., "Road centrality and landscape spatial patterns in Wuhan Metropolitan Area, China," Chinese Geographical Science, vol. 25, no. 4, pp. 511-522, 2015.

[112] J. Scheurer, C. Curtis, and S. Porta, Spatial network analysis of multimodal transport systems: developing a strategic planning tool to assess the congruence of movement and urban structure: a case study of perth before and after the perth-to-mandurah railway, GAMUT, Australasian Centre for the Governance and Management of Urban Transport, University of Melbourne, 2008.

[113] C. Curtis and J. Scheurer, "Planning for sustainable accessibility: developing tools to aid discussion and decision-making," Progress in Planning, vol. 74, no. 2, pp. 53-106, 2010.

[114] J. Yang, J. Zhu, Y. Sun, and J. Zhao, "Delimitating urban commercial central districts by combining kernel density estimation and road intersections: a case study in nanjing city, china," ISPRS International Journal of Geo-Information, vol. 8, no. 2, article 93, 2019.

[115] Ö. Bodin and S. Saura, "Ranking individual habitat patches as connectivity providers: Integrating network analysis and patch removal experiments," Ecological Modelling, vol. 221, no. 19, pp. 2393-2405, 2010.

[116] M. Pereira, P. Segurado, and N. Neves, "Using spatial network structure in landscape management and planning: a case study with pond turtles," Landscape and Urban Planning, vol. 100, no. 1-2, pp. 67-76, 2011.

[117] S. Saura, P. Vogt, J. Velázquez, A. Hernando, and R. Tejera, "Key structural forest connectors can be identified by combining landscape spatial pattern and network analyses," Forest Ecology and Management, vol. 262, no. 2, pp. 150-160, 2011.

[118] L. Tischendorf and L. Fahrig, "On the usage and measurement of landscape connectivity," Oikos, vol. 90, no. 1, pp. 7-19, 2000.

[119] J. Cheng, L. Bertolini, F. L. Clercq, and L. Kapoen, "Understanding urban networks: comparing a node-, a density- and an accessibility-based view," Cities, vol. 31, pp. 165-176, 2013.

[120] J.-C. Foltête, X. Girardet, and C. Clauzel, "A methodological framework for the use of landscape graphs in land-use planning," Landscape and Urban Planning, vol. 124, pp. 140-150, 2014.

[121] A. Zetterberg, U. M. Mörtberg, and B. Balfors, "Making graph theory operational for landscape ecological assessments, planning, and design," Landscape and Urban Planning, vol. 95, no. 4, pp. 181-191, 2010.

[122] C. Tannier, J.-C. Foltête, and X. Girardet, "Assessing the capacity of different urban forms to preserve the connectivity of ecological habitats," Landscape and Urban Planning, vol. 105, no. 1-2, pp. 128-139, 2012.

[123] A. M. Lechner, V. Doerr, R. M. B. Harris, E. Doerr, and E. C. Lefroy, "A framework for incorporating fine-scale dispersal behaviour into biodiversity conservation planning," Landscape and Urban Planning, vol. 141, pp. 11-23, 2015.
[124] H. L. Mossman, C. J. Panter, and P. M. Dolman, "Modelling biodiversity distribution in agricultural landscapes to support ecological network planning," Landscape and Urban Planning, vol. 141, pp. 59-67, 2015.

[125] E. Vaz and J. Aversa, "A graph theory approach for geovisualization of anthropogenic land-use change: an application to lisbon," Journal of Spatial and Organizational Dynamics, vol. 1, no. 4, pp. 254-264, 2013.

[126] P. Wu, H. Gong, and D. Zhou, "Identification of key changed land use type in LUCC: a case study of guishui river basin," in Proceedings of the 20th International Conference on Geoinformatics, 2012.

[127] P. Wu, H. Gong, and D. Zhou, "Land use and land cover change in watershed of Guanting Reservoir based on complex network," Acta Geographica Sinica, vol. 67, no. 1, pp. 113-121, 2012.

[128] D. M. Levinson, F. Xie, and S. Zhu, "The co-evolution of landuse and road networks," Transportation and Traffic Theory, pp. 839-859, 2007.

[129] M. Iacono, D. Levinson, and A. El-Geneidy, "Models of transportation and land use change: a guide to the territory," Journal of Planning Literature, vol. 22, no. 4, pp. 323-340, 2008.

[130] D. Levinson and B. Yerra, "How land-use shapes the evolution of road networks," SSRN, Article ID 1736160, 2005.

[131] D. Levinson and B. Yerra, "Self-organization of surface transportation networks," Transportation Science, vol. 40, no. 2, pp. 179-188, 2006.

[132] F. Xie and D. Levinson, "Measuring the structure of road networks," Geographical Analysis, vol. 39, no. 3, pp. 336-356, 2007.

[133] F. Xie and D. Levinson, "Topological evolution of surface transportation networks," Computers, Environment and Urban Systems, vol. 33, no. 3, pp. 211-223, 2009.

[134] B. M. Yerra and D. M. Levinson, "The emergence of hierarchy in transportation networks," Annals of Regional Science, vol. 39, no. 3, pp. 541-553, 2005.

[135] T. Li, H. Sun, J. Wu et al., "Optimal urban expressway system in a transportation and land-use interaction equilibrium framework," Transportmetrica A: Transport Science, pp. 1-31, 2019.

[136] T. Li, J. Wu, H. Sun, and Z. Gao, "Integrated co-evolution model of land-use and traffic network design," Networks and Spatial Economics, pp. 1-25, 2015.

[137] J. Wu, R. Li, R. Ding, T. Li, and H. Sun, "City expansion model based on population diffusion and road growth," Applied Mathematical Modelling, 2016.

[138] R. Li, J. Wu, H. Liu et al., "Crowded urban traffic: co-evolution among land development, population, roads and vehicle ownership," Nonlinear Dynamics, pp. 1-13, 2018.

[139] C. Zhong, S. M. Arisona, X. Huang, M. Batty, and G. Schmitt, "Detecting the dynamics of urban structure through spatial network analysis," International Journal of Geographical Information Science, vol. 28, no. 11, pp. 2178-2199, 2014.

[140] M. Kurant and P. Thiran, "Layered complex networks," Physical Review Letters, vol. 96, no. 13, Article ID 138701, 2006.

[141] S. V. Buldyrev, R. Parshani, G. Paul, H. E. Stanley, and S. Havlin, "Catastrophic cascade of failures in interdependent networks," Nature, vol. 464, no. 7291, pp. 1025-1028, 2010.

[142] S.-R. Albert, G. Sergio, and A. Alex, "Congestion induced by the structure of multiplex networks," Physical Review Letters, vol. 116, no. 10, Article ID 108701, 2016. 
[143] C.-G. Gu, S.-R. Zou, X.-L. Xu et al., "Onset of cooperation between layered networks," Physical Review E, vol. 84, no. 2, article 026101, 2011.

[144] A. Aleta, S. Meloni, and Y. Moreno, "A multilayer perspective for the analysis of urban transportation systems," Scientific Reports, vol. 7, article 44359, 2016.

[145] R. Gallotti, A. Bazzani, S. Rambaldi, and M. Barthelemy, How Transportation Hierarchy Shapes Human Mobility, 2015.

[146] E. Strano, S. Shai, S. Dobson, and M. Barthelemy, "Multiplex networks in metropolitan areas: generic features and local effects," Journal of the Royal Society Interface, vol. 12, no. 111, Article ID 20150651, 2015.

[147] R. Ding, N. Ujang, H. B. Hamid et al., "Heuristic urban transportation network design method, a multilayer coevolution approach," Physica A: Statistical Mechanics and its Applications, vol. 479, pp. 71-83, 2017.

[148] R. G. Morris and M. Barthelemy, "Transport on coupled spatial networks," Physical Review Letters, vol. 109, no. 12, Article ID 128703, 2012.

[149] R. Ding, N. Ujang, H. B. Hamid et al., "Detecting the urban traffic network structure dynamics through the growth and analysis of multi-layer networks," Physica A: Statistical Mechanics and its Applications, vol. 503, pp. 800-817, 2018.

[150] S. Shamsuddin and N. Ujang, "Making places: the role of attachment in creating the sense of place for traditional streets in Malaysia," Habitat International, vol. 32, no. 3, pp. 399-409, 2008.

[151] N. Ujang, Place Attachment Towards Shopping Districts in Kuala Lumpur City Centre, Universiti Putra Malaysia, Malaysia, 2008.

[152] N. Ujang, "Place attachment and continuity of urban place identity," Asian Journal of Environment-Behaviour Studies, vol. 1, no. 2, pp. 61-76, 2010.

[153] N. Ujang, "Place attachment and continuity of urban place identity," Procedia - Social and Behavioral Sciences, vol. 49, pp. 156-167, 2012.

[154] S. Lin, B. de Schutter, Y. Xi, and H. Hellendoorn, "Fast model predictive control for urban road networks via MILP," IEEE Transactions on Intelligent Transportation Systems, vol. 12, no. 3, pp. 846-856, 2011.

[155] Y.-Y. Liu, J.-J. Slotine, and A.-L. Barabási, "Controllability of complex networks," Nature, vol. 473, no. 7346, pp. 167-173, 2011.

[156] J. Gao, B. Barzel, and A.-L. Barabási, "Universal resilience patterns in complex networks," Nature, vol. 530, no. 7590, pp. 307-312, 2016.

[157] A. Bergsten and A. Zetterberg, "To model the landscape as a network: a practitioner's perspective," Landscape and Urban Planning, vol. 119, pp. 35-43, 2013. 


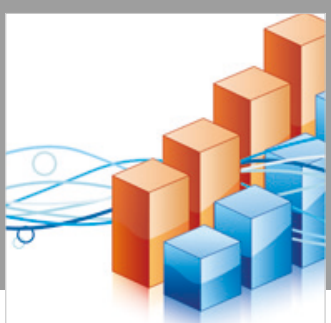

Advances in

Operations Research

\section{-n-m}
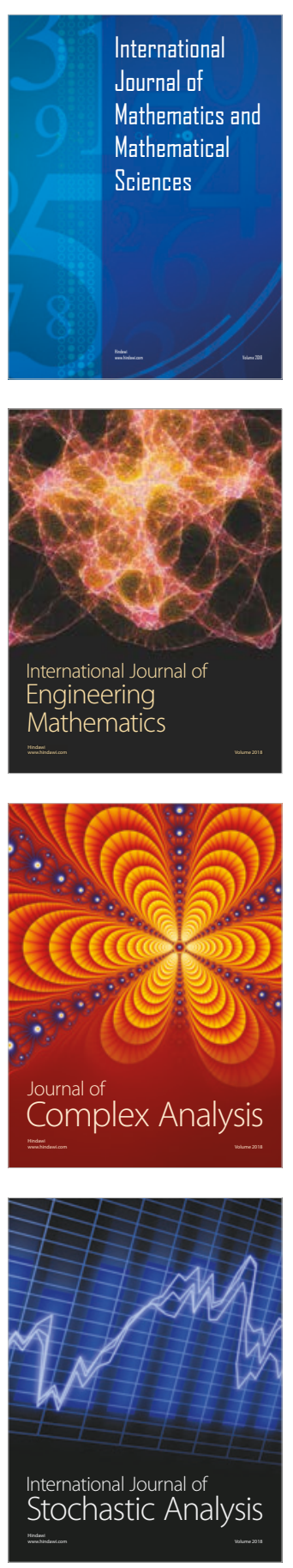
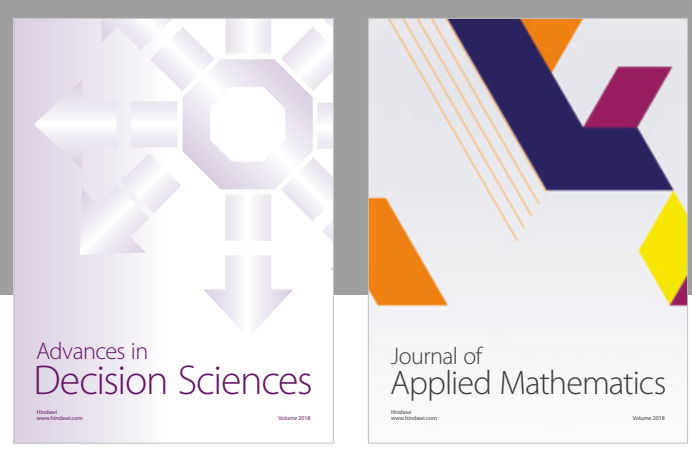

Journal of

Applied Mathematics
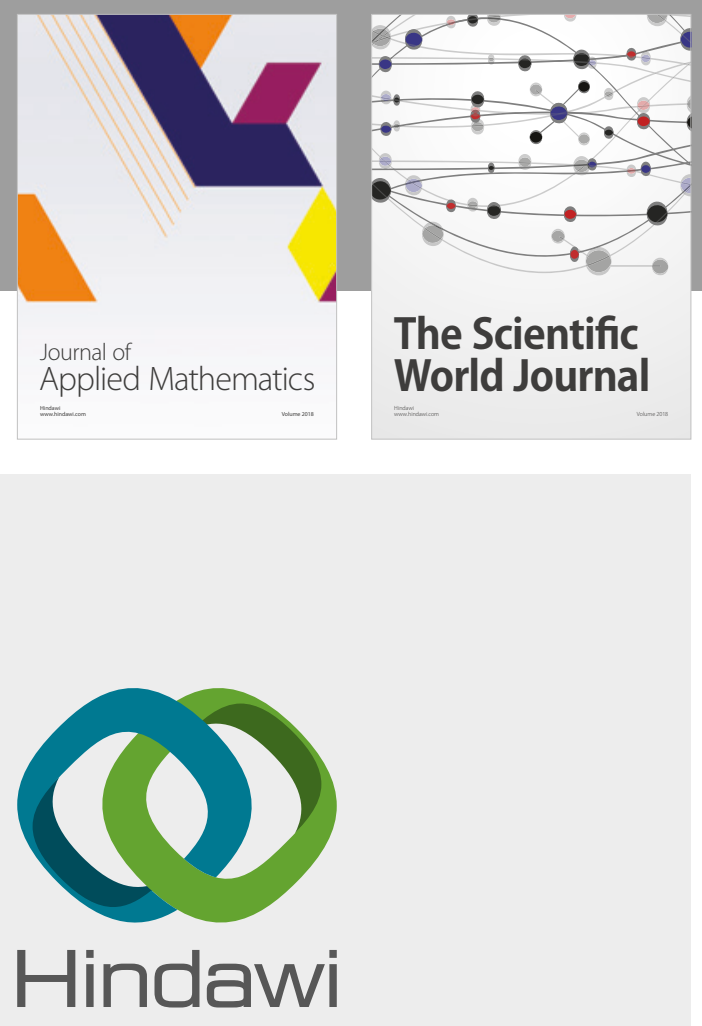

Submit your manuscripts at

www.hindawi.com

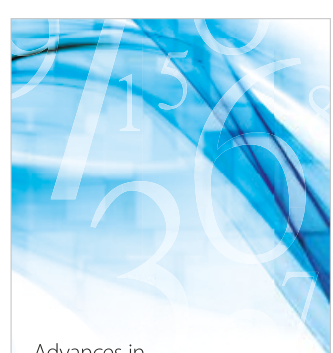

Advances in
Numerical Analysis
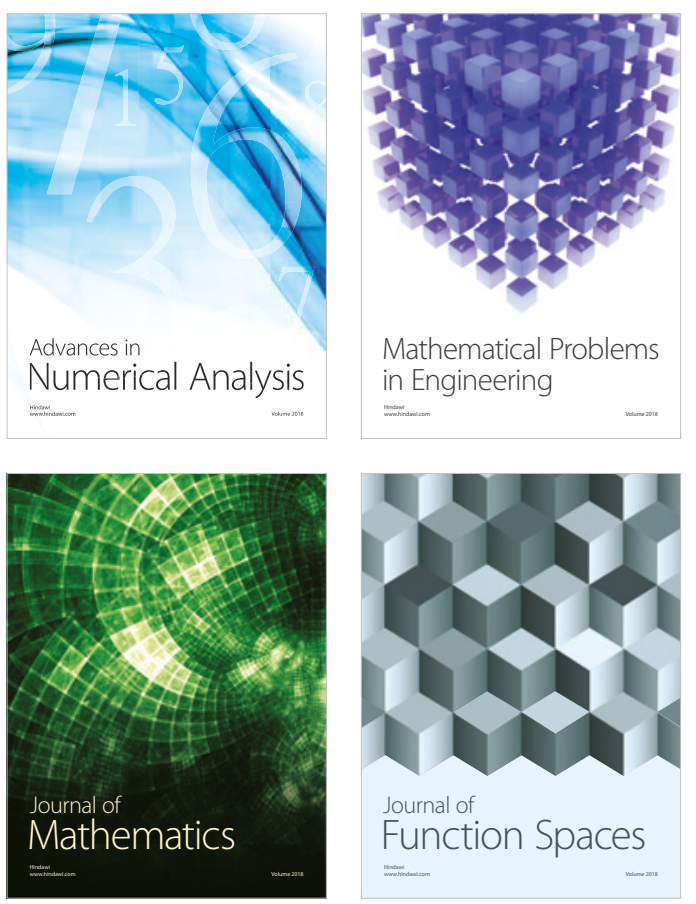

Mathematical Problems in Engineering

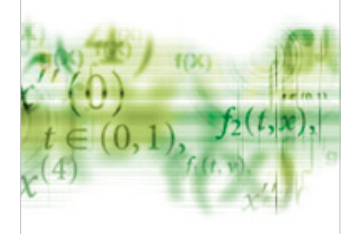

International Journal of

Differential Equations

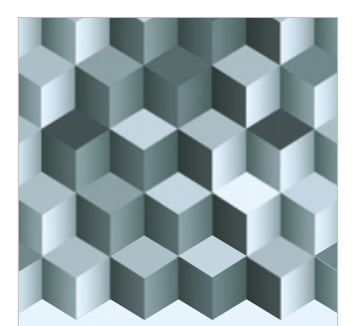

Journal of

Function Spaces
The Scientific

World Journal

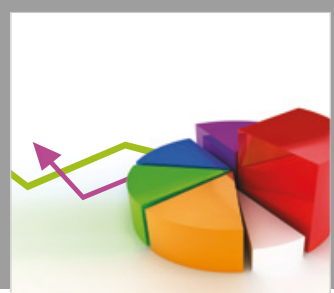

Journal of

Probability and Statistics
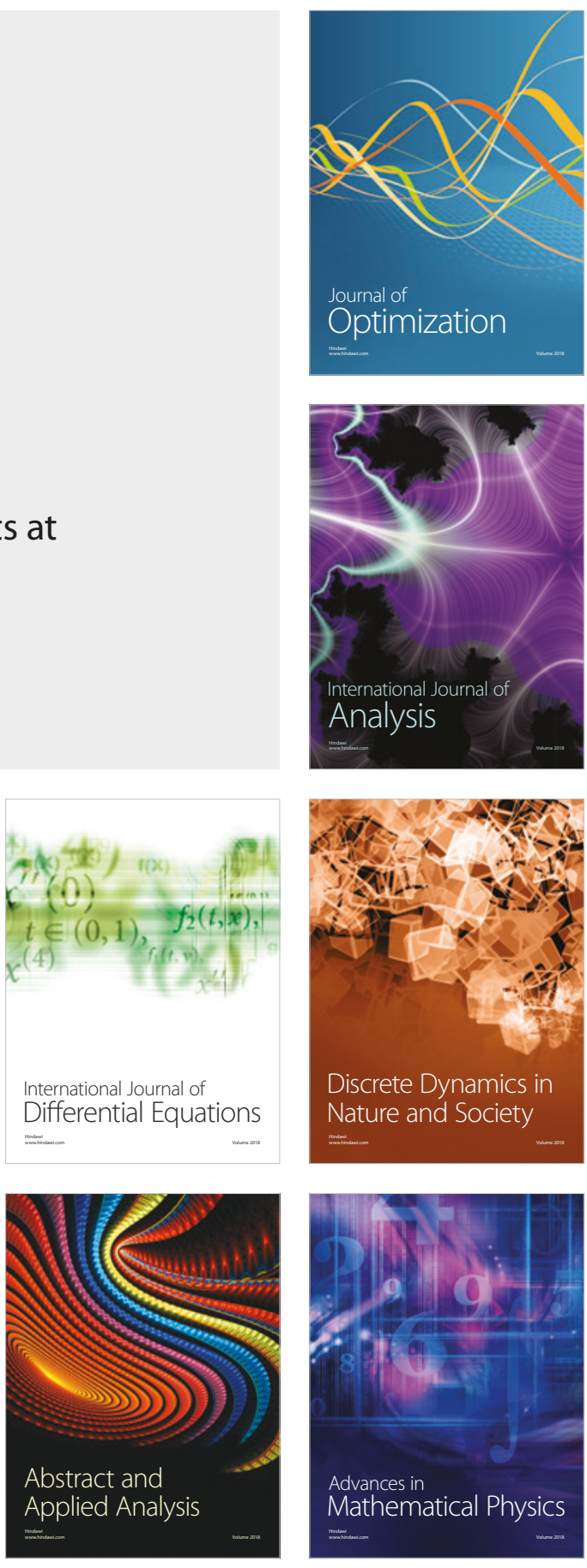